\title{
Assessing and analysing the impact of land take pressures on arable land
}

\author{
Ece Aksoy $^{1}$, Mirko Gregor ${ }^{2}$, Christoph Schröder ${ }^{1}$, Manuel Löhnertz $^{2}$, and Geertrui Louwagie ${ }^{3}$ \\ ${ }^{1}$ European Topic Centre on Urban, Land and Soil systems (ETC/ULS), University of Malaga, Malaga, Spain \\ ${ }^{2}$ ETC/ULS, space4environment, Niederanven, Luxembourg \\ ${ }^{3}$ European Environment Agency (EEA), Copenhagen, Denmark
}

Correspondence to: Ece Aksoy (ece.aksoy@uma.es, eceaksoy@hotmail.com)

Received: 8 November 2016 - Discussion started: 25 November 2016

Revised: 10 March 2017 - Accepted: 14 May 2017 - Published: 20 June 2017

\begin{abstract}
Land, and in particular soil, is a finite and essentially non-renewable resource. Across the European Union, land take, i.e. the increase of settlement area over time, annually consumes more than $1000 \mathrm{~km}^{2}$ of which half is actually sealed and hence lost under impermeable surfaces. Land take, and in particular soil sealing, has already been identified as one of the major soil threats in the 2006 European Commission Communication "Towards a Thematic Strategy on Soil Protection" and the Soil Thematic Strategy and has been confirmed as such in the report on the implementation of this strategy. The aim of this study is to relate the potential of land for a particular use in a given region with the actual land use. This allows evaluating whether land (especially the soil dimension) is used according to its (theoretical) potential. To this aim, the impact of several land cover flows related to urban development on soils with good, average, and poor production potentials were assessed and mapped. Thus, the amount and quality (potential for agricultural production) of arable land lost between the years 2000 and 2006 was identified. In addition, areas with high productivity potential around urban areas, indicating areas of potential future land use conflicts for Europe, were identified.
\end{abstract}

\section{Introduction}

Land use in Europe has changed drastically during the last 50 years, primarily in relation to the betterment of human well-being and economic development, while unfortunately causing serious environmental problems such as ur- ban sprawl, soil sealing, loss of biodiversity, soil erosion, soil degradation, floods, or desertification.

The changes in land use can also be interpreted as changes in the resources, services, and goods that soils offer to us; moreover, the type of land use change varies among different types of regions. Smith et al. (2015) describe the effects of land use changes (increased change of arable to urban) on different ecosystem services that are provided by soil decreased biomass and decreased availability of water for agricultural use (provisioning services); decreased infiltration, storage, and soil-mediated water regulation (regulating services); decreased genetic diversity (supporting service); and decreased natural environment (cultural service).

Land use changes are a worldwide issue and the impacts of land use changes are the subject of several studies. In recent years, several modelling and foresight studies of land use change have emerged with European research projects, such as VOLANTE - Visions of Land Use Transitions in Europe (EU FP7 project), EU-LUPA - European Land Use Patterns (ESPON project), SENSOR - Sustainable Impact Assessment Tools for Environmental, Social and Economic Effects of Multifunctional Land Use in European Regions (EU FP6 integrated project) (Helming et al., 2006), enviroGRIDS (EU FP7 project), the ATEAM EU FP5 project (Advanced Terrestrial Ecosystem Analysis and Modelling to search global climate and land use change impacts on ecosystem vulnerability in Europe (Rounsevell et al., 2006), the EURURALIS project - addressing socio-economic impacts associated with land use changes in the agricultural sector (Klijn et al., 2005), the SEAMLESS project - approach for multi-scale modelling to asses sustainability impacts of agricultural policies (van It- 
tersum et al., 2008), and the PRELUDE project of the European Economic Area (EEA) on scenarios for future land use changes in Europe (Hoogeven and Ribeiro, 2007). In the following, we give some examples from the literature on the impacts of land use change. Mancosu et al. (2015) develop different land use change scenarios and discusses their impacts on the Black Sea region. Parras-Alcántara et al. (2013) examine the impacts of land use change on soil carbon and nitrogen in a Mediterranean agricultural area. Adugna and Abegaz (2016) discuss the effects of land use changes on the soil properties in Ethiopia. Mohawesh et al. (2015) reveal the effects of land use changes on soil properties in Jordan and results help in understanding the effects of land use changes on land degradation processes and carbon sequestration potential and in formulating sound soil conservation plans. Wasak and Drewnik (2015) studied the land use effects on soil organic carbon sequestration in calcareous Leptosols in the Tatra Mountains, Poland. Muñoz-Rojas et al. (2015) analysed the long time series (1956-2007) impacts of land use and land cover changes on organic carbon stocks in Mediterranean soils. Liu et al. (2014) studied land use and climate changes and their impacts on runoff in the Yarlung Tsangbo River basin, China. Kalema et al. (2015) showed the impacts of land use changes on woodlands in an equatorial African savanna. Lastly, Trabaquini et al. (2015) examined the effects of the land use changes of physical soil properties in the Brazilian savanna environment.

Land take represents an increase in artificial surfaces or settlement areas (for residential, commercial, industrial, or infrastructural purposes, for example) over time, usually at the expense of rural areas. This process can result in an increase in scattered settlements in rural regions or in an expansion of urban areas around an urban nucleus (urban sprawl, which is defined as "the physical pattern of low-density expansion of large urban areas, under market conditions, mainly into the surrounding agricultural areas"; EEA, 2006a). A clear distinction is usually difficult to make (Prokop et al., 2011).

Land take is a widespread phenomenon in Europe. The assessment as part of the EEA indicator land take (CSI 014/LSI 001) identifies extension of artificial land cover as one of the two major flows that consume arable land; the other one is withdrawal of farming, which is supported by European policies (EEA, 2006a). Tóth (2012) analysed the impact of land take on soil productivity using the Joint Research Center (JRC) Cropland Productivity Index map and combined it with Corine Land Cover (CLC) changes and socio-economic data. He concluded that the European Union (EU) experiences a constant decrease in production capacity (Tóth, 2012).

Soils are used to produce a range of biomass products that serve as food, feed, fibre, and fuel. Biomass production can be particularly relevant in biodiversity conservation and climate change mitigation efforts, through supporting elements of green infrastructure and flood regulation (EEA, 2015).
Biomass production is one of the soil functions recognized in the EU (CEC, 2006) and is severely affected by land take. Urbanized land is not mainly used for agriculture, and furthermore, a large proportion of the land taken for urbanization is actually sealed. Soil sealing can be considered as an almost irreversible process, since "de-sealing" is very costly and the formation of new soil takes decades, i.e. $1 \mathrm{~cm}$ in 100 years (Scheffer and Schachtschabel, 2002). Accordingly, soil functions are commonly considered as lost when soils are covered with impervious surfaces.

From the agricultural point of view, land take is a soilland loss for non-agricultural purposes, so that in a way its effect is similar to soil degradation (caused by severe erosion) and might be considered as a complementary process. It is important to recognize why it is of interest to compare different categories of soil biomass productivity affected by land take and how these classes are connected to soil erosion and degradation. Therefore, the aim of this study is to assess and analyse the impacts of several land cover flows related to urban development (referred to as land take) between the years 2000 and 2006 on soils with good, average, and poor biomass production potentials and identify regions with major impact (hotspots) in Europe.

\section{Material and methods}

\subsection{Material}

The main input data for this study are

- soil biomass productivity data on arable land (Tóth et al., 2013).

- land cover and use data (CORINE, 2017).

- land cover and changes (CLC changes and derived land cover flows (LCFs) between the years 2000 and 2006) (EEA, 2013c).

The soil biomass productivity map on arable land was produced with the spatially explicit Soil Productivity Model (SoilProd) for Europe by JRC (Tóth et al., 2011) (Fig. 1). This map provides composite cropland productivity index scores, which are expressed on a scale from 1 to 10. Score 1 represents the lowest and 10 the highest biomass production potential. The productivity index is the sum of the inherent soil productivity index and the fertilizer response rate. The former results from an evaluation matrix set up for eight climatic zones, five inherent productivity classes (derived from second level taxonomic soil units), soil attribute information from the soil database (corrected for topographic conditions), and four available water capacity classes. The fertilizer response rate takes account of the management practices applied. More details about the model and the map production process can be found in Tóth (2012) and Tóth et al. (2011). 


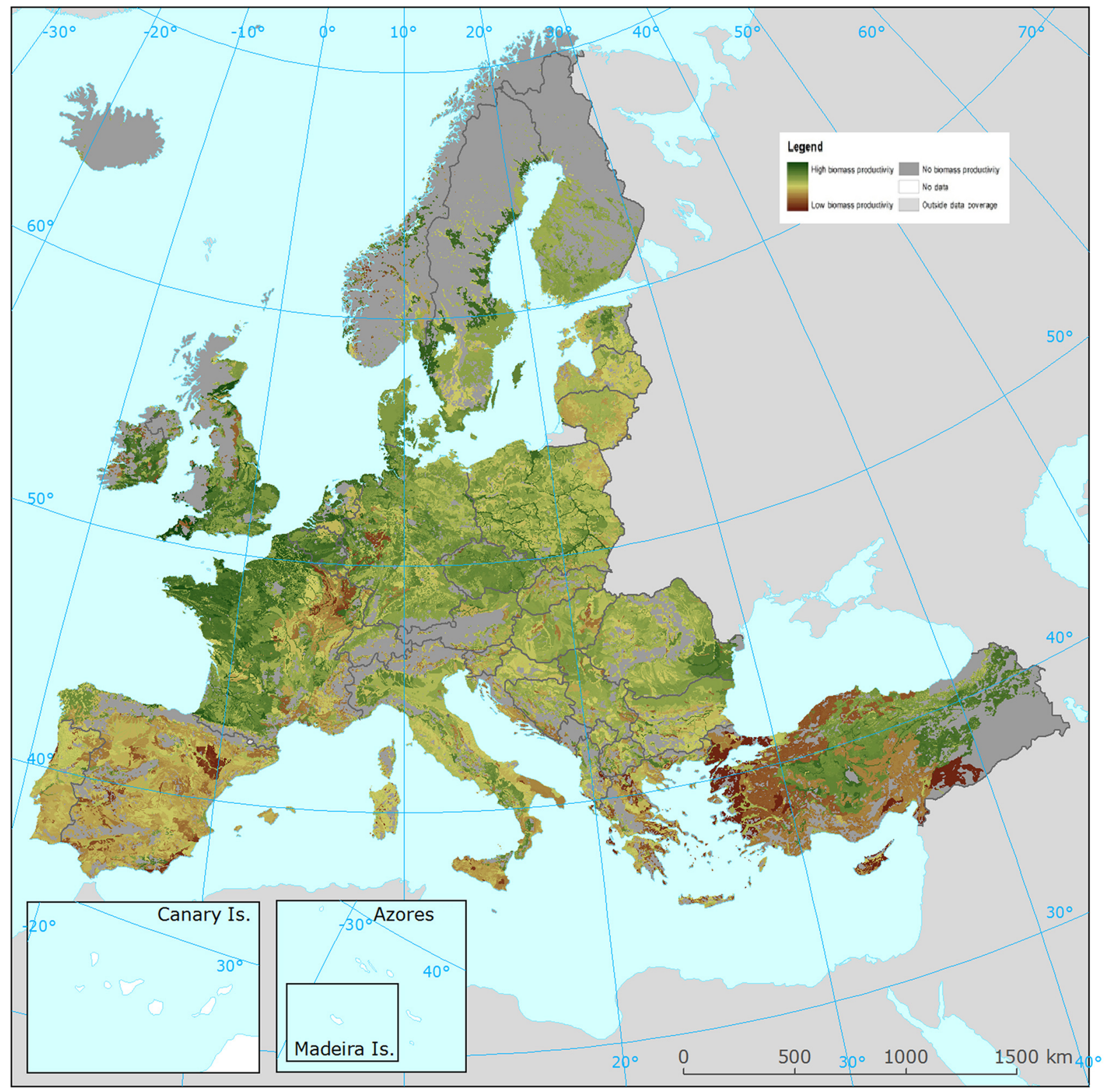

Figure 1. Soil productivity data on arable land (pan-European grid layer) (JRC). Legend shows high biomass productivity (green) to low biomass productivity (brown), no biomass productivity (dark grey), no data (white), and outside data coverage (light grey).

The soil biomass productivity data were provided by JRC, $1 \mathrm{~km}^{2}$ raster data sets have full coverage of Europe but they are only valid for the corresponding land use types. Therefore, the appropriate CLC classes (based on CLC-Corilis 2000) were identified to build the masks for the extraction of the soil and/or land productivity layers. The CLC classes we used are 2.1 "Arable land" (subclasses 211 "Nonirrigated arable land", 212 "Permanently irrigated land", and 213 "Rice fields") and 2.4 "Heterogeneous agricultural ar- eas" (subclasses 241 "Annual crops associated with permanent crops" and 242 "Complex cultivation patterns") (Tóth, 2012).

There are nine major LCFs on Level 1 (Land and Ecosystem Accounting, LEAC, 2000-2006) (EEA, 2013a) (Table 1). The combination of the land take flows LCF2 and LCF3 (urban residential sprawl and extension of economic sites and infrastructure) were used for this study. The impact 
Table 1. Major land cover flows (LCFs) on Level 1 (EEA, 2013a).

\begin{tabular}{ll}
\hline Code & Major type of cover change \\
\hline LCF1 & Urban land management \\
LCF2 & Urban residential sprawl \\
LCF3 & Extension of economic sites and infrastructure \\
LCF4 & Agriculture internal conversions \\
LCF5 & Conversion from forested and natural land to agriculture \\
LCF6 & Withdrawal of farming \\
LCF7 & Forest creation and management \\
LCF8 & Water body creation and management \\
LCF9 & Changes of land cover due to natural and multiple causes \\
\hline
\end{tabular}

calculation for Greece could not be done because of not having CLC 2006 and LCFs.

The technical assessment of land take on arable land is based on the land cover flows as described below:

- The definition of LCF2 is as follows: urban residential sprawl consists of land uptake by residential buildings altogether with associated services and urban infrastructure (classified in CLC 111 and 112) from non-artificial land (extension over sea may happen). Two subcategories are distinguished, namely urban dense residential sprawl resulting in continuous urban fabric and urban diffuse residential sprawl resulting in discontinuous urban fabric.

- The definition of LCF3 is as follows: sprawl of economic sites and infrastructures consists of land uptake by new economic sites and infrastructures (including sport and leisure facilities) from non-artificial land (extension over sea may happen). This land cover flow includes eight subcategories, namely sprawl of the following infrastructure on non-urban land, i.e. industrial and commercial sites, transport networks, harbours, airports, mines and quarries, dump sites, construction, and sport and leisure facilities (EEA, 2013a).

\subsection{Method}

The schematic workflow of the study can be seen in Fig. 2 . Four main steps were followed to assess the impacts of land take pressures on arable land analysis.

First of all, the soil biomass productivity data were classified into soils with good, average, and poor capacities to provide biomass on arable land (step 1, Fig. 2) with the aim of easier analysis, interpretation, and calculation. This classification is performed based on the value distribution and their statistical parameters. This means that the lower third of all values are classified as poor (class 1), the upper third as good (class 3), and the values in between as average (class 2).

Secondly, a mask was applied to the soil biomass productivity map (step 2, Fig. 2) by using defined CLC classes according to the provisions of Tóth (2012). Then, after the clas-

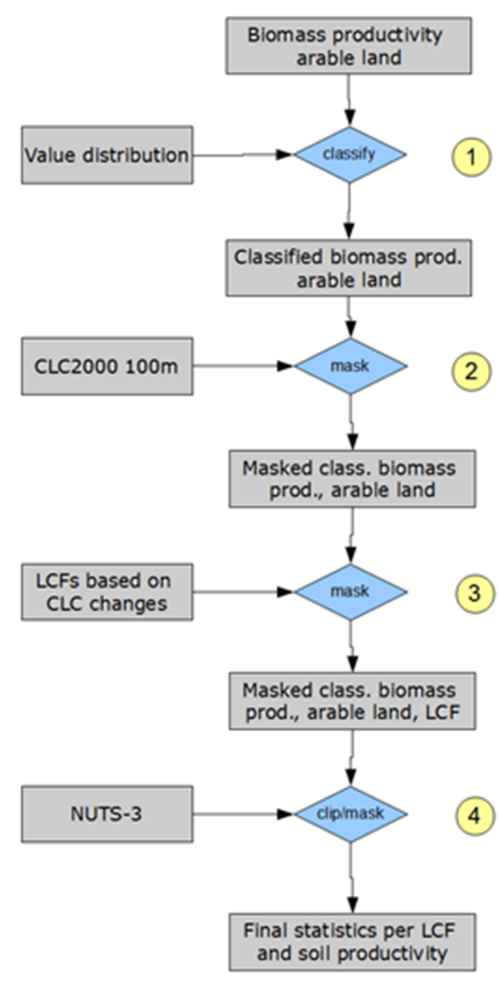

Figure 2. Schematic workflow of the study.

sification and masking processes, the selected LCFs were overlaid onto the masked and classified data to extract the raster cells that contain a land cover change that is relevant for the analysis. This process in fact represents another masking process, as described in Fig. 2 (step 3). Lastly, the raster data were combined with the NUTS- 3 reference units to compute the zonal statistics for each of the parameter combinations (impact of a particular LCF or combination of LCFs on a particular soil function potential (Fig. 2, step 4).

The final value of the impact of a particular LCF or combination of LCFs on the capacity of soils to supply a particular soil function is expressed in relation to the share of that specific soil function potential in the NUTS-3 region. This means that the share of, for example, good soils within a NUTS-3 region, is the reference for the calculation, not the entire area of the NUTS-3 region.

Moreover, for interpretation purposes the value ranges can be understood and verbally described regarding their impact (expressed as percentages) as follows (ranked from very low to very high impact; green to red colours in Fig. 5):

- very low impact

- low impact

- intermediate impact

- high impact and

- very high impact. 


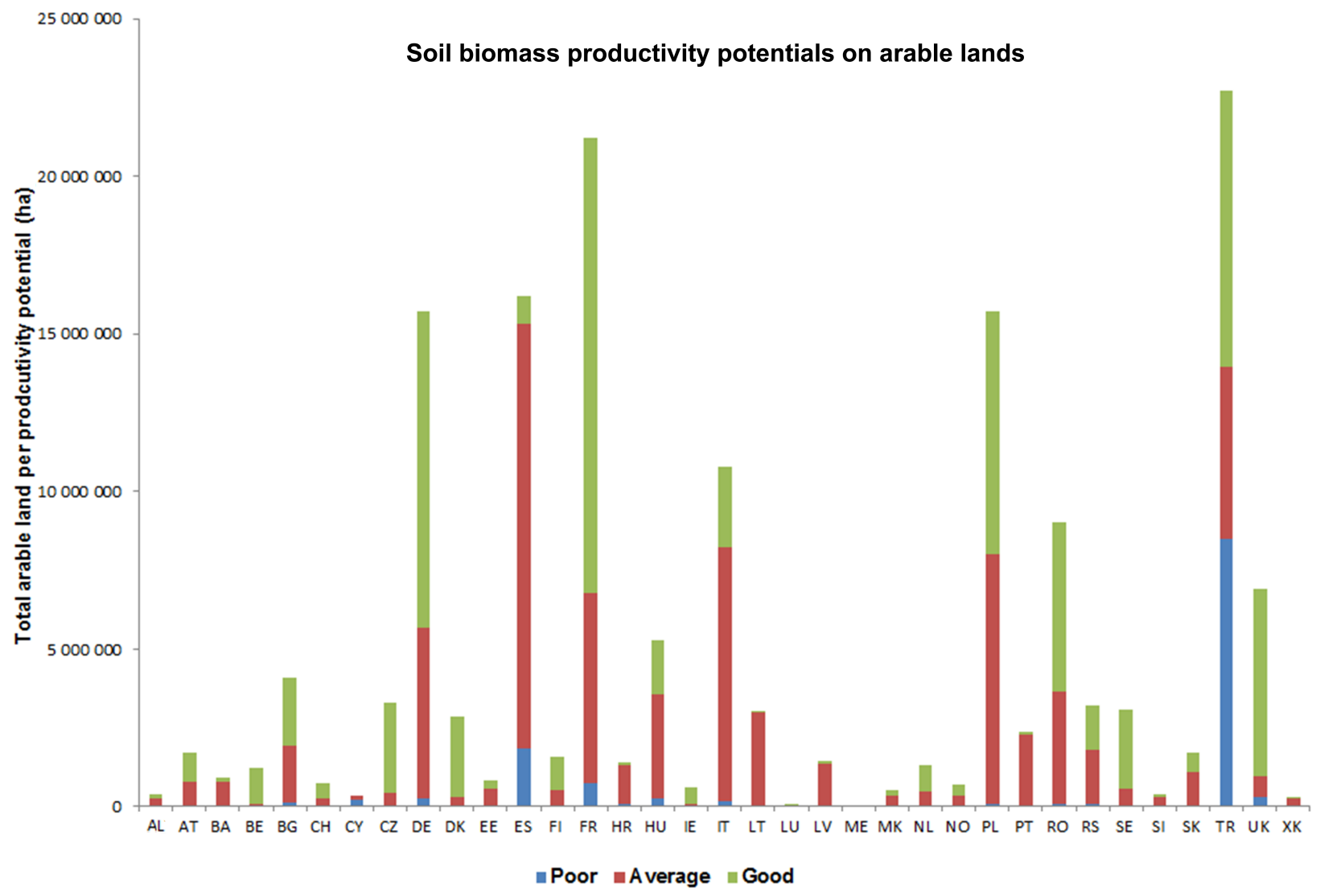

Figure 3. Graphic presentation of soil biomass productivity potentials on arable land for each country.

In addition, the descriptions of the outcomes make reference to relative and absolute impacts. Whereas relative impacts correspond to the percentage values of the impact of a certain LCF on soils of a specific capacity in a NUTS-3 region, the absolute impacts refer to the area (in hectares) that is affected by a particular LCF. Depending on the size of the reference unit (that is, the area of soils of a specific capacity in a NUTS3 region) high absolute values do not necessarily correspond to high relative values, while low absolute values could well mean high relative values (when the total size of the reference area is very small).

\section{Results}

According to the results given in Table 2 and Fig. 3, even though the highest share of the total arable land coverage of the whole country is higher than $40 \%$ in the Czech Republic, Germany, Denmark, Hungary, Lithuania, Poland, and Serbia, Turkey, France, Spain, Germany, and Poland each have over 15000000 ha of arable land. Moreover, close to half $(46.32 \%)$ of the arable lands in the whole study area and half of the countries (18 out of 36 countries) have good productivity potentials. Over $80 \%$ of the arable land in Belgium (BE), the Czech Republic (CZ), Denmark (DK), Ireland (IE),
Sweden (SE), and the United Kingdom (UK) have good productivity potential. Over $80 \%$ of the arable land in Bosnia and Herzegovina (BA), Spain (ES), Croatia (HR), Lithuania (LT), Latvia (LV), Portugal (PT), and Kosovo (XK) have average productivity potential. Only one country, Cyprus, has mostly poor biomass productivity potential on its arable land.

The distribution of the soils according to their potential for biomass production on arable land per NUTS-3 area can be seen in Fig. 4; the proportions are given in relation to the total area of each individual NUTS-3 region. By consequence, the maps nicely illustrate where poor, average, or good soils dominate in Europe and where they are only of minor importance.

Soils that are considered poor for biomass production on arable land mainly dominate in three European regions, (i) Spain, (ii) central and north-eastern France, and (iii) south-eastern Europe (almost all of Turkey and large parts of Greece). Almost all other regions have an intermediate to low share of poor soils for the provision of biomass on arable land. Of the first 20 NUTS-3 regions across Europe, 14 are located in Turkey (Fig. 4). The others are located in the UK, France, and Cyprus (NUTS-3 region boundary corresponds to the entire country). However, most of the men- 
Table 2. Statistical distribution of arable lands according to their biomass production potential for each country (bold font shows the major share). Abbreviations of the countries are as follows: AL - Albania, AT - Austria, BA - Bosnia and Herzegovina, BE - Belgium, BG Bulgaria, CH - Switzerland, CY - Cyprus, CZ - Czech Republic, DE - Germany, DK - Denmark, EE - Estonia, EL - Greece, ES - Spain, FI - Finland, FR - France, HR - Croatia, HU - Hungary, IE - Ireland, IT - Italy, LT - Lithuania, LU - Luxembourg, LV - Latvia, ME - Montenegro, MK - Macedonia, NL - the Netherlands, NO - Norway, PL - Poland, PT - Portugal, RO - Romania, RS - Serbia, SE Sweden, SI - Slovenia, SK - Slovakia, TR - Turkey, UK - the United Kingdom, and XK - Kosovo.

\begin{tabular}{|c|c|c|c|c|c|c|}
\hline \multirow[t]{2}{*}{ Country } & \multirow{2}{*}{$\begin{array}{l}\text { Country } \\
{\left[\mathrm{km}^{2}\right]}\end{array}$} & \multirow{2}{*}{$\begin{array}{r}\text { Total arable } \\
\text { land } \\
{\left[\mathrm{km}^{2}\right]}\end{array}$} & \multirow{2}{*}{ 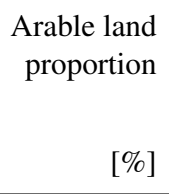 } & \multicolumn{3}{|c|}{$\begin{array}{l}\text { Soil biomass productivity } \\
\text { potential per total arable land }\end{array}$} \\
\hline & & & & $\begin{array}{r}\text { Poor } \\
{[\%]}\end{array}$ & $\begin{array}{r}\text { Average } \\
{[\%]}\end{array}$ & $\begin{array}{r}\text { Good } \\
{[\%]}\end{array}$ \\
\hline $\mathrm{AL}$ & 28755.06 & 3729.06 & 12.97 & 6.99 & 65.48 & 27.53 \\
\hline AT & 83947.82 & 17291.73 & 20.6 & 0.93 & 43.96 & 55.11 \\
\hline BA & 51399.37 & 9032.91 & 17.57 & 3.2 & 84.69 & 12.11 \\
\hline $\mathrm{BE}$ & 30664.19 & 12123.74 & 39.54 & 0.25 & 7.32 & 92.43 \\
\hline BG & 110988.76 & 41120.23 & 37.05 & 2.81 & 44.65 & 52.54 \\
\hline $\mathrm{CH}$ & 41287.33 & 7605.61 & 18.42 & 1.31 & 31.71 & 66.98 \\
\hline $\mathrm{CY}$ & 9249.11 & 3468.26 & 37.5 & 62 & 38 & 0 \\
\hline $\mathrm{CZ}$ & 78869.52 & 33054.4 & 41.91 & 0.19 & 13.15 & 86.66 \\
\hline DE & 357737.29 & 157211.86 & 43.95 & 1.58 & 34.41 & 64.01 \\
\hline DK & 43174.76 & 28487.19 & 65.98 & 0.09 & 11.33 & 88.58 \\
\hline $\mathrm{EE}$ & 45335.44 & 8338.46 & 18.39 & 1.39 & 65.76 & 32.84 \\
\hline EL & 131735.85 & 28320.05 & 21.5 & 12.47 & 74.54 & 12.99 \\
\hline ES & 505980.28 & 161978.31 & 32.01 & 11.51 & 83.08 & 5.41 \\
\hline FI & 337616.92 & 15956.63 & 4.73 & 0.7 & 32.69 & 66.61 \\
\hline FR & 638480.71 & 212195.3 & 33.23 & 3.58 & 28.45 & 67.97 \\
\hline $\mathrm{HR}$ & 56599.65 & 13861.69 & 24.49 & 4.85 & 91.22 & 3.93 \\
\hline HU & 93012.99 & 52795.47 & 56.76 & 4.9 & 62.96 & 32.13 \\
\hline IE & 69956.69 & 6336.24 & 9.06 & 7.42 & 9.04 & 83.54 \\
\hline IT & 300620.28 & 107714.14 & 35.83 & 1.78 & 74.5 & 23.72 \\
\hline LT & 64901.2 & 30396.19 & 46.83 & 0.09 & 98.45 & 1.46 \\
\hline LU & 2595.06 & 847.7 & 32.67 & 13.37 & 38.21 & 48.41 \\
\hline LV & 64596.24 & 14582.72 & 22.58 & 1.26 & 91.14 & 7.6 \\
\hline $\mathrm{ME}$ & 13878.81 & 166.5 & 1.2 & 20.16 & 32.64 & 47.2 \\
\hline MK & 25436.12 & 5191.04 & 20.41 & 3.9 & 64.16 & 31.95 \\
\hline NL & 37373.99 & 13059.17 & 34.94 & 1.25 & 36.62 & 62.13 \\
\hline $\mathrm{NO}$ & 323024.51 & 7033.67 & 2.18 & 3.97 & 46.07 & 49.97 \\
\hline PL & 311942.39 & 157056.55 & 50.35 & 0.47 & 50.49 & 49.04 \\
\hline PT & 91969.54 & 23630.11 & 25.69 & 2.33 & 94.53 & 3.14 \\
\hline RO & 238364.06 & 90033.96 & 37.77 & 1.12 & 39.45 & 59.43 \\
\hline $\mathrm{RS}$ & 77313.57 & 32165.26 & 41.6 & 3.06 & 53.01 & 43.93 \\
\hline SE & 449563.7 & 30977.11 & 6.89 & 0.83 & 17.69 & 81.48 \\
\hline SI & 20273.58 & 3900.67 & 19.24 & 2.41 & 79.7 & 17.9 \\
\hline SK & 49027.63 & 17085.84 & 34.85 & 0.38 & 64.04 & 35.58 \\
\hline TR & 780290.77 & 226986.37 & 29.09 & 37.49 & 23.93 & 38.58 \\
\hline UK & 244619.49 & 68939.64 & 28.18 & 4.68 & 9.15 & 86.17 \\
\hline XK & 11004.64 & 2877.41 & 26.15 & 0.99 & 94.53 & 4.48 \\
\hline Grand total & 5821587.32 & 1645551.2 & 28.27 & 8.23 & 45.45 & 46.32 \\
\hline
\end{tabular}

tioned regions show very low to intermediate impact of urban expansion; Cyprus shows a high impact though.

Average soils for arable biomass provision are widespread across Europe and can be found in large parts of Spain and Italy, Hungary, Poland, and the southern Baltic countries (Lithuania and Latvia). Regions of Germany, France, Bulgaria, and Greece also possess average soils. Low shares of average soils can be found in Turkey, parts of Greece, Bulgaria and Romania, the Czech Republic, parts of Germany and France, the UK, and Scandinavia. The number of NUTS3 regions with a high to very high share of average soils for biomass provision on arable land (Fig. 3) is substantially higher compared to those with a high share of poor soils. There are 32 regions that have a majority share, that is, more 


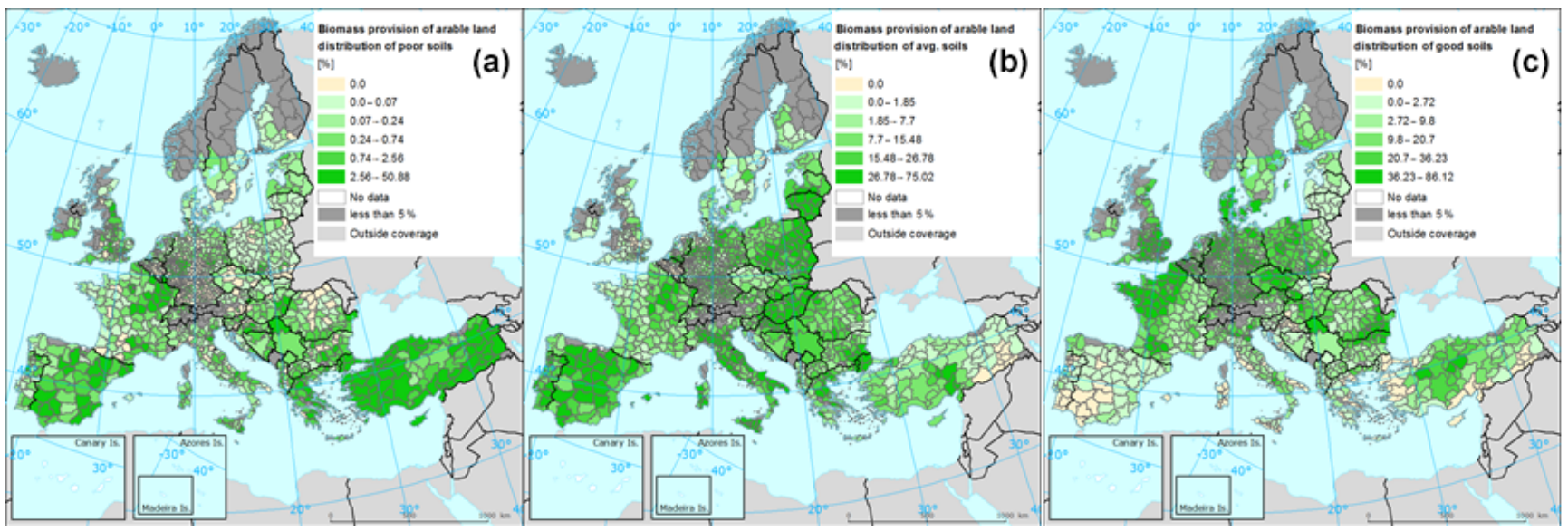

Figure 4. Distribution of soils according to their potential for biomass production on arable land: proportions of poor (a), average (b), and good (c) soils (in \% of the total NUTS-3 region area). Legend shows the shares (\%) from low (light green) to high (dark green), "0" (light yellow), no data (white), less than $5 \%$ (dark grey), and outside data coverage (light grey). "Less than $5 \%$ " means that the total area of arable land is smaller than $5 \%$. Note that the same colours might represent different percentages as quantiles were used during the map production. Ranges are given between 0 and $50.88 \%$ (a), between 0 and $75.02 \%$ (b), and between 0 and $86.12 \%$ (c).

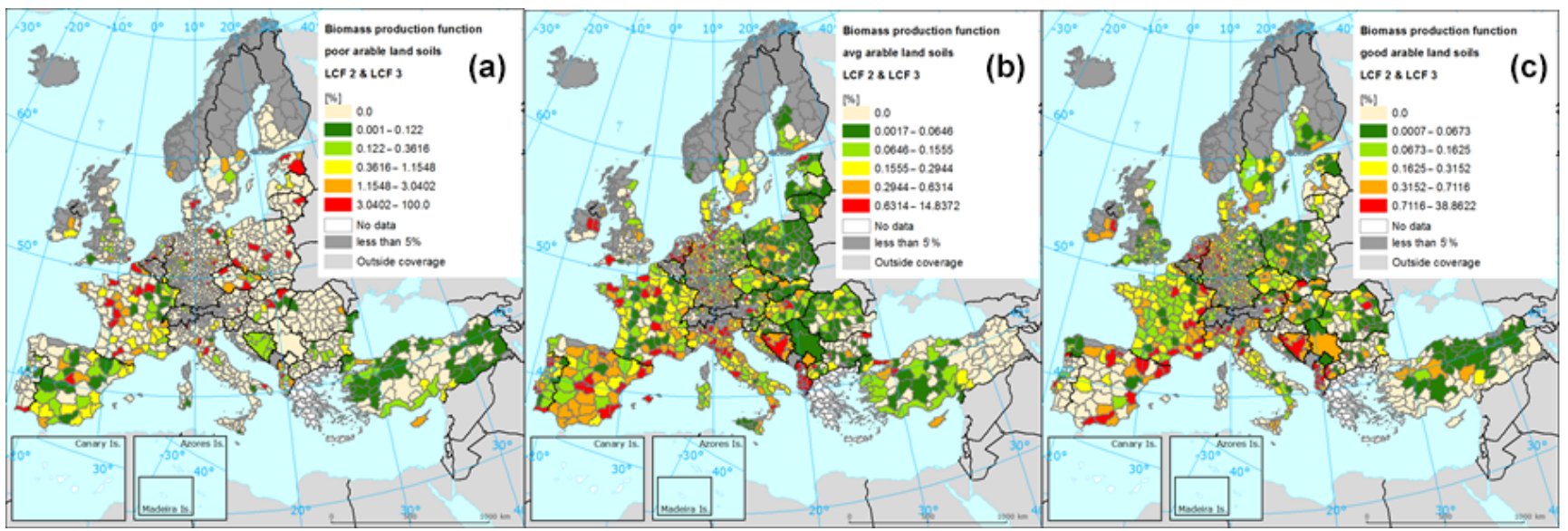

Figure 5. Percentage decline (per NUTS-3 area) of arable land area with poor (a), average (b), and good (c) production potentials due to urban residential, commercial, industrial, and infrastructure-related extension (LCF2 and LCF3) between 2000 and 2006. Legend shows the shares (\%) from low (dark green) to high (red), "0" (light yellow), no data (white), less than $5 \%$ (dark grey), and outside data coverage (light grey). "Less than $5 \%$ " means that the total area of arable land is smaller than $5 \%$. Note that the same colours might represent different percentages as quantiles were used during the map production. Ranges are given between 0.001 and $100 \%$ (a), between 0.017 and $14.84 \%$ (b), and between 0.001 and $38.86 \%$ (c).

than $50 \%$, in the respective NUTS-3 region (only one NUTS3 region for poor soils), with the highest values of over $70 \%$ in one Spanish (ES418, Valladolid) and two Italian regions (ITH36 and ITH57, Padua and Ravenna, respectively). In general, there is a high share of Italian regions (12 NUTS-3 regions), which are often located in or close to the Po Valley, which used to be one of the most fertile areas in Europe; another remarkable hotspot is Lithuania with 5 regions.

Good soils for the provision of biomass on arable land dominate in large parts of north-western Europe, such as lots of regions in the UK, north-western France, the Benelux countries, Germany, Denmark, Poland, Czech Republic,
Hungary, and Bulgaria. Even some regions in central Turkey have a high share of good soils. Low shares can be found mainly in the western Balkan countries, the Iberian Peninsula, Romania, the Baltic countries and some regions in Finland and Sweden. Compared to the average soils, the number of NUTS-3 regions with a very high share of good soils is even bigger; almost 140 regions have a majority share of good soils, with the upper seven regions exceeding $80 \%$ (four regions in the UK, two in Romania, and one in Germany) (Fig. 4).

The highest land take impacts on the biomass productivity potentials of arable land were found in Albania 
Table 3. Statistical distribution of the land take impact on arable land for each country between 2000 and 2006. Abbreviations of the countries are as follows: AL - Albania, AT - Austria, BA - Bosnia and Herzegovina, BE - Belgium, BG - Bulgaria, CH - Switzerland, CY - Cyprus, CZ - the Czech Republic, DE - Germany, DK - Denmark, EE - Estonia, ES - Spain, FI - Finland, FR - France, HR - Croatia, HU - Hungary, IE - Ireland, IT - Italy, LT - Lithuania, LU - Luxembourg, LV - Latvia, ME - Montenegro, MK - Macedonia, NL - the Netherlands, NO - Norway, PL - Poland, PT - Portugal, RO - Romania, RS - Serbia, SE - Sweden, SI - Slovenia, SK - Slovakia, TR - Turkey, UK - the United Kingdom, and XK - Kosovo).

\begin{tabular}{|c|c|c|c|c|c|c|c|c|c|}
\hline \multirow[t]{2}{*}{ Country } & \multirow[t]{2}{*}{$\begin{array}{r}\text { Total arable } \\
\text { land (ha) }\end{array}$} & \multirow[t]{2}{*}{$\begin{array}{l}\text { Total impact on } \\
\text { arable land (ha) }\end{array}$} & \multicolumn{3}{|c|}{$\begin{array}{l}\text { Impact on arable } \\
\text { land (ha) }\end{array}$} & \multirow[t]{2}{*}{$\begin{array}{l}\text { Total impacted } \\
\text { arable land (\%) }\end{array}$} & \multicolumn{3}{|c|}{$\begin{array}{l}\text { Arable land }(\%) \\
\text { impact on total }\end{array}$} \\
\hline & & & Poor & Avg & Good & & Poor & Avg & Good \\
\hline $\mathrm{AL}$ & 372906 & 14795 & 539 & 8672 & 5584 & 3.97 & 2.07 & 3.55 & 5.44 \\
\hline AT & 1729173 & 4137 & 20 & 1478 & 2639 & 0.24 & 0.12 & 0.19 & 0.28 \\
\hline BA & 903291 & 5329 & 61 & 4100 & 1168 & 0.59 & 0.21 & 0.54 & 1.07 \\
\hline $\mathrm{BE}$ & 1212374 & 2027 & 7 & 111 & 1909 & 0.17 & 0.23 & 0.13 & 0.17 \\
\hline BG & 4112023 & 1920 & 145 & 1289 & 486 & 0.05 & 0.13 & 0.07 & 0.02 \\
\hline $\mathrm{CH}$ & 760561 & 784 & 12 & 157 & 615 & 0.10 & 0.12 & 0.07 & 0.12 \\
\hline CY & 346826 & 4816 & 4087 & 729 & 0 & 1.39 & 1.90 & 0.55 & 0.00 \\
\hline $\mathrm{CZ}$ & 3305440 & 8390 & 103 & 900 & 7387 & 0.25 & 1.64 & 0.21 & 0.26 \\
\hline $\mathrm{DE}$ & 15721186 & 47620 & 1605 & 16053 & 29962 & 0.30 & 0.65 & 0.30 & 0.30 \\
\hline DK & 2848719 & 9250 & 18 & 1001 & 8231 & 0.32 & 0.69 & 0.31 & 0.33 \\
\hline $\mathrm{EE}$ & 833846 & 1522 & 491 & 929 & 102 & 0.18 & 4.23 & 0.17 & 0.04 \\
\hline ES & 16197831 & 71338 & 7211 & 59786 & 4341 & 0.44 & 0.39 & 0.44 & 0.50 \\
\hline FI & 1595663 & 1207 & 0 & 246 & 961 & 0.08 & 0.00 & 0.05 & 0.09 \\
\hline FR & 21219530 & 52096 & 2919 & 12376 & 36801 & 0.25 & 0.38 & 0.20 & 0.26 \\
\hline HR & 1386169 & 1409 & 0 & 1389 & 20 & 0.10 & 0.00 & 0.11 & 0.04 \\
\hline HU & 5279547 & 11382 & 374 & 7469 & 3539 & 0.22 & 0.14 & 0.22 & 0.21 \\
\hline IE & 633624 & 4806 & 193 & 765 & 3848 & 0.76 & 0.41 & 1.34 & 0.73 \\
\hline IT & 10771414 & 37484 & 179 & 26747 & 10558 & 0.35 & 0.09 & 0.33 & 0.41 \\
\hline LT & 3039619 & 2522 & 17 & 2472 & 33 & 0.08 & 0.64 & 0.08 & 0.07 \\
\hline LU & 84770 & 177 & 75 & 37 & 65 & 0.21 & 0.66 & 0.11 & 0.16 \\
\hline LV & 1458272 & 316 & 42 & 243 & 31 & 0.02 & 0.23 & 0.02 & 0.03 \\
\hline $\mathrm{ME}$ & 16650 & 1 & 0 & 1 & 0 & 0.01 & 0.00 & 0.02 & 0.00 \\
\hline MK & 519104 & 1330 & 6 & 712 & 612 & 0.26 & 0.03 & 0.21 & 0.37 \\
\hline NL & 1305917 & 18874 & 213 & 6943 & 11718 & 1.45 & 1.30 & 1.45 & 1.44 \\
\hline NO & 703367 & 557 & 20 & 244 & 293 & 0.08 & 0.07 & 0.08 & 0.08 \\
\hline PL & 15705655 & 14246 & 622 & 6629 & 6995 & 0.09 & 0.85 & 0.08 & 0.09 \\
\hline PT & 2363011 & 7099 & 79 & 6840 & 180 & 0.30 & 0.14 & 0.31 & 0.24 \\
\hline $\mathrm{RO}$ & 9003396 & 5828 & 59 & 2178 & 3591 & 0.06 & 0.06 & 0.06 & 0.07 \\
\hline $\mathrm{RS}$ & 3216526 & 2430 & 0 & 792 & 1638 & 0.08 & 0.00 & 0.05 & 0.12 \\
\hline SE & 3097711 & 5728 & 99 & 734 & 4895 & 0.18 & 0.38 & 0.13 & 0.19 \\
\hline SI & 390067 & 332 & 11 & 280 & 41 & 0.09 & 0.12 & 0.09 & 0.06 \\
\hline SK & 1708584 & 2660 & 0 & 1445 & 1215 & 0.16 & 0.00 & 0.13 & 0.20 \\
\hline TR & 22698637 & 16761 & 7153 & 4259 & 5349 & 0.07 & 0.08 & 0.08 & 0.06 \\
\hline UK & 6893964 & 8832 & 671 & 1552 & 6609 & 0.13 & 0.21 & 0.25 & 0.11 \\
\hline XK & 287741 & 840 & 0 & 832 & 8 & 0.29 & 0.00 & 0.31 & 0.06 \\
\hline Total & 161723114 & 368845 & 27031 & 180390 & 161424 & 0.23 & 0.2 & 0.25 & 0.21 \\
\hline
\end{tabular}

(AL) $(3.97 \%)$, the Netherlands (NL) (1.45\%), Cyprus (CY) $(1.39 \%)$, and Ireland (IE) $(0.76 \%)$ (Table 3 and Fig. 6). However, when expressing the impacts on an absolute (in hectare) rather than on a relative (in percentage) basis, Spain, France, and Germany rank highest (with 71338,52096 , and 47620 ha, respectively). Thus, even though the relative impact may be low in some countries, the absolute impact may be quite high. For example, while the share of land with good and average productivity potentials is very similar $(0.5$ and $0.44 \%$, respectively), the total area of land with good productivity potential is far lower (4341 ha) than that of average productivity potential (59786 ha) (Table 3 ). Therefore, it is better to consider the absolute and relative values in parallel.

Figure 5 describes the impact of land take (the combination of LCF2 and LCF3, i.e. residential, commercial, industrial, and infrastructure-related extension) on arable land 


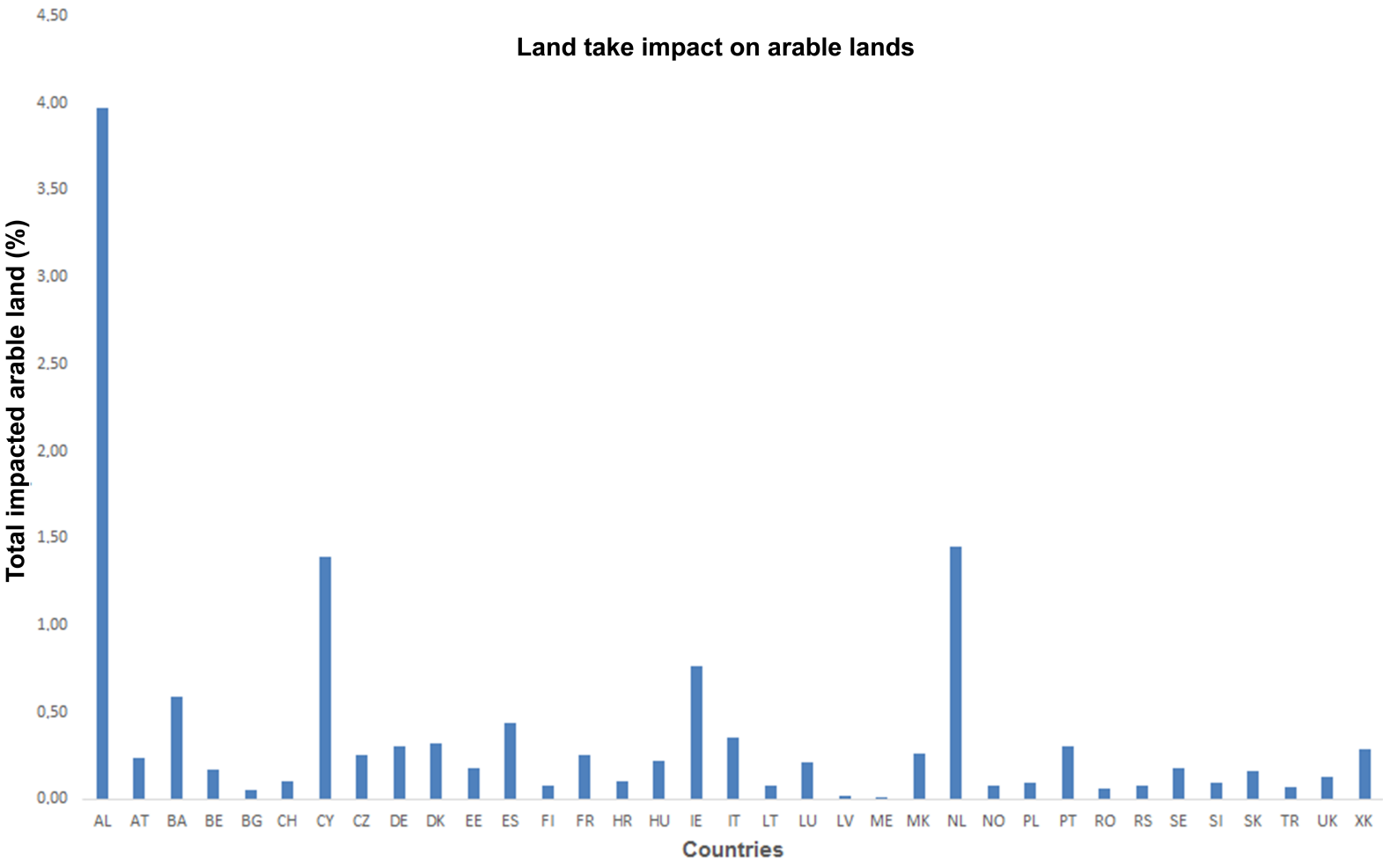

Figure 6. Graphic presentation of land take impact on arable land for each country.

with poor, average, and good potentials for the provision of biomass.

In general, the map illustrates that regions with a very high impact of urban land take on poor soils are scattered across Europe; there is no geographic area with a striking clustering of such regions. However, the south-eastern part of Europe only contains a few NUTS-3 regions with a high impact: Cyprus, Istanbul, and one region in Romania (Galati, RO224). Also, Albania possesses some regions with a high to very high impact of urban land take. Conversely, the NUTS3 regions with the highest relative impact still possess only low to very low shares of poor soils within the NUTS-3 regions. Most of these regions are located in north-western $\mathrm{Eu}-$ rope (the UK, Ireland, and Germany), some isolated ones can be found in south-western France, Italy, and Poland. When looking at absolute impacts (in terms of total area affected) of urban expansion on poor arable soils, four regions, located in southern Europe, stand out. Except for Seville (ES618), all other regions (Cyprus, Istanbul, and Valladolid) also have high to very high relative impacts.

Figure 5 clearly shows that, on the one hand, regions with a high to very high impact of urban expansion activities on average soils are distributed across Europe, but that, on the other hand, some clusters exist. Most striking is Albania, which comprises the two regions with the highest relative impact (AL00B and AL002, Tirana and Durres, with 14.8 and $12.1 \%$, respectively); followed by the Netherlands, Ger- many, Italy, and Spain, which also possess a number of regions with a very high impact of urban land take on average soils.

In terms of absolute values, only a few of the previous regions are among the highest ranking. Interestingly, both Albanian regions also possess a large absolute value (2752 and 1997 ha, respectively). However, the region with by far the highest absolute value is the region of Madrid (ES300), with 11854 ha of average soils lost due to land take, which corresponds to $5.2 \%$ in relative terms. The absolute value of Madrid is more than double that of the second highest region, which is another Spanish region (Toledo), followed by two other Spanish regions (Ciudad Real and Zaragoza). Remarkably, many more Spanish regions follow in the ranking. This implies a very high absolute loss of average soils due to land take, but often with less relevance when it comes to the relative impact (often intermediate, sometimes high values regarding the share of soils with average potential in a particular NUTS-3 area).

Regarding the distribution of regions with a very high impact of land take on good soils, some clusters of regions and/or hotspots exist. One is located in the Netherlands and western Germany, another one in the western Balkans (including Albania), a third one from northern Italy (Umbria and Po valleys) to south-eastern France (Alpes and Provence, Rhone Valley), a fourth one on the Iberian Peninsula, and a fifth one in Ireland. The relative impact ranges from $38.9 \%$ 
in Tirana (AL00B) over $34.7 \%$ (NL332, Agglomeratie 'sGravenhage), $27.7 \%$ (NL327, Het Gooi en Vechtstreek), and $15 \%$ (NL325, Zaanstreek) to several regions between 10.6 and $5 \%$ of an impact.

In terms of absolute values, most of those regions with very high relative impact values do not score very high, though. Only two Albanian regions as well as one Irish region stand out. Otherwise, there are five other regions (next to Tirana, AL00B) that have more than 2000 ha of impacted good soils on arable land. Three of those regions are located in France, one in Turkey, and one in the Czech Republic. In terms of relative impacts, they possess intermediate to high values (between 0.34 and $0.81 \%$ ). Interestingly, many of the high-ranked regions possess a share of more than $50 \%$ of good soils; however, there are also some regions with a very low share. One of those regions is again Tirana with a share of $3.4 \%$; others are AL00A (Shkoder, $5.5 \%$ ) and ES523 (Valencia, $4.3 \%)$. The latter two also show very high relative values of the impact of land take on the good soils, that is, of the limited area with good soils available, a high share is affected by land take.

\section{Discussion}

In general, most of the arable lands have good productivity potentials, both at country level (18 countries out of 36) and when considering the entire coverage of the study area $(46.32 \%)$.

However, the European picture is, as expected, very heterogeneous. The urban residential expansion and extension of economic sites and infrastructure activities is spatially distributed across Europe, with very low (green) to very high (red) impact on the biomass productivity of arable land. Several hotspot areas can be identified in which land take clearly affects soils with a capacity to provide biomass.

The highest share of arable land affected by land take was found in Albania (AL) (3.97\%), the Netherlands (NL) $(1.45 \%)$, Cyprus (CY) $(1.39 \%)$, and Ireland (IE) $(0.76 \%)$. However, when the impacted lands are considered in hectare, Spain, France, and Germany are the highest ranked. High and very high impacts on good land can mainly be detected in regions in Ireland, Spain, France, Germany, Italy, and the Balkan countries. Average land is strongly impacted in Albania, the Netherlands, Germany, and Italy. Very high impacts of urban land take on poor soils are scattered across Europe.

When taking the gross domestic product of the outstanding regions into account, there seems to be no direct relation to the economic situation of a region. Both well-developed and less-developed regions experience high to very high impacts of land-take-related land cover flows on the soil productivity.

Several hotspot areas are identified in which land take clearly affects soils with a capacity to provide biomass. The Madrid region is one of the hotspots of urban development in Europe, experiencing a rate of $50 \%$ growth in the 1990s, compared to $25 \%$ national and $5.4 \%$ EU average rates (EEA, 2006a). The trend attenuated between 2000 and 2006 (around $20 \%$ ) but is still present. According to Díaz-Pacheco and García-Palomares (2014) the urban land surface grew at a rate in excess of $4 \%$ per year. Tóth (2012) shows that the urban sprawl of Madrid occurred to a large extent on arable land. According to the EEA report (EEA, 2006a) major drivers are (i) the growing demand for first and second homes caused by economic growth and low interest rates despite a rather modest population growth; (ii) increased mobility; (iii) increasing housing prices, which force more people to move further and further into the city suburbs; and (iv) a weak planning framework. The reasons for land take differ from country to country; nevertheless, these major drivers that were given for the Madrid region might be valid for most of the regions or countries in Europe with the addition of some drivers such as new developments along transportation axes, tourism, and coastline diffusion in general. Moreover, the OECD reports (OECD, 2007) that rapid and partly unplanned development led to urban sprawl in the Madrid region.

Alongside the situation in the Madrid region, the EEA (EEA, 2006a) also presents the example of the occurring urban sprawl along the Spanish and Portuguese coastlines. In these areas, sprawl mainly consists of diffuse settlements adjacent to or disconnected from concentrated urban centres. This residential sprawl is responsible for more than $45 \%$ of coastal zone land transformation into artificial surfaces. In Portugal, $50 \%$ of urban areas are located between LisbonSetubal and Porto-Viana do Castelo within $13 \mathrm{~km}$ from the shoreline, hence covering only $13 \%$ of the total land area. In Spain economic growth, legislative flexibility, and tourism resulted in an increased number of households and second homes along the coast, in combination with infrastructure and leisure facility development.

Outside the Iberian Peninsula, the Po Valley and the adjacent Emilia-Romagna Plain (ERP) have a long history of urban expansion. The valley has soils that are amongst the most fertile in Europe. Even though the entire region is called "Food Valley", more and more of its agricultural area is irreversibly converted into urban fabric, either for residential or industrial and commercial use, continuing at a rate of 1 ha per day (EC, 2011). The movie "Il suolo minacciato" ("Land under threat") presented during Green Week 2011 uses the example of these two confronting pressures on land to highlight what is currently happening in this region. Malucelli et al. (2014) confirm that while the extent of woodland, grassland, natural areas, and wetlands in the ERP did not change significantly, urban and industrial areas increased to the detriment almost exclusively of cropland. The analysis in the current study highlights that mainly good and average land is affected.

The impacts of land take on regions in southern France are also already described and explained in the EEA report on urban sprawl (EEA, 2006a). This so-called "inverse T" of 
urban sprawl along the Rhone Valley down to the Mediterranean coast is caused by new developments along transportation axes and coastlines (which are often connected to river valleys).

Another prominent and well-known region of urban sprawl and related land take is the Dublin metropolitan area, which can be recognized on the maps of average and good soils. In the past, population growth and economic development were responsible for the expansion of the metropolitan area further to the outskirts (EEA, 2006a).

In Germany, land take is most prominent in the region comprising the "Ruhrgebiet" (in particular the regions around its core), in parts of southern Germany, but also in eastern Germany, particularly in some regions that are experiencing an improvement in their economic situation (e.g. Leipzig). Prokop et al. (2011) state that despite having defined a target of reducing land take to 30 ha day $^{-1}$ until 2020, the measures taken so far have not been sufficient.

In the Netherlands most regions have experienced and are still experiencing rapid urban expansion along the urbanrural fringes during the past decades, which is still ongoing, although spatial planning policies were seeking to promote compact urban developments (Nabielek et al., 2013). This increase in land take is also documented in Prokop et al. (2011), showing the constant increase in built-up area between the 1960s and 2006 (Fig. 49 in Prokop et al., 2011). A similar picture appears in the Flanders region (Belgium), where the typical ribbon development continues at a rate of 6 ha per day of which 5 ha is due to residential sprawl (Gregor et al., 2015).

Regarding the conversion of arable land to urbanized areas in the central and eastern European countries, it can be assumed that the accession to the EU in 2004 and the related economic development together with benefits from regional development programmes were the leading driving forces to the expansion of residential, but mainly industrial and commercial, areas, primarily at the expense of good and average lands. Very recent statistics on the cohesion funding amount allocated per member state (EC, 2015) confirm that some of the eastern European countries rank amongst the top. For example, Poland is the country with the highest amount allocated, while the Czech Republic and Hungary rank fourth and sixth, respectively.

Without being a member state of the EU, Albania has undergone significant changes with regards to urban expansion and land take. In particular, average and good soils for providing biomass on arable land have been converted into artificial surfaces, according to the most recent assessment of the EEA (2013b) on land take indicator coded CSI 014. This has happened at the expense of grassland and mixed farmland (in total $73 \%$ of the total land uptake), which is of relevance in this context of arable land. Likewise, in Bosnia and Herzegovina $72 \%$ of the total land take occurred on grassland or mixed farmland areas.

\section{Conclusion}

The potentials and the actual use of the lands were linked, and impact of land take on arable lands with good, average, and poor production potentials were assessed and mapped successfully by this study. According to the results, from 2000 to $20060.23 \%$ of the production potential on arable land in the study area was lost as a consequence of land take; over the period 1990-2006, this loss amounted to $0.81 \%$ (EEA, 2015). Especially the arable lands that have good production potential and have been impacted by land take can be considered as lands that have not been used according to their theoretical potentials. This situation of arable lands with high productivity potentials is creating pressure on soils and other ecosystem types, resulting in threats to soil biodiversity, all other soil functions, and ecosystem services. Since Europe is approaching a time when being able to demonstrate good land resource management will be critical for food security and achieving other soil protection and land degradation neutrality targets, this situation is getting attention. Moreover, the countries and hotspot regions that have the highest land take impact on the biomass productivity potentials of arable land, was indicated by this study, can be considered as the areas that also have potential future land use conflicts. Therefore, assessment and mapping of the land take impacts on arable land for the 2006-2012 period is essential to understanding the trends of the countries and to monitor the situation.

Interpreting the assessment results and observing the spatial distribution of the small number of impacts on this scale was quite hard. Even though the impacts were calculated based on pixels, interpreting them on NUTS-3 units was helpful. Also, considering the absolute (in hectares) and relative (as a percentage) values in parallel is important because of the different coverages of the countries. It should be remembered that, even though the relative impact may be low in some countries, the absolute impact may be quite high.

Data availability. The soil productivity data on arable land are publicly accessible on the JRC ESDAC web page (http://esdac.jrc.ec.europa.eu/content/soil-biomass-productivitymaps-grasslands-and-pasture-coplands-and-forest-areas-european; ESDAC, 2017). The land cover flow data are publicly accessible on the EEA web page for the years 1990-2000 (https://www.eea.europa.eu/data-and-maps/data/land-coverflows-based-on-corine-land-cover-changes-database-1990-2000-1; EEA, 2006b). The methodology for the year 2000-2006 is available on the following web page: https://www.eea.europa. eu/data-and-maps/figures/dominant-land-cover-flow-2000-2006 (EEA, 2013c). All Corine Land Cover and Corine Land Cover Changes raster layers are publicly accessible on the following web page: http://land.copernicus.eu/pan-european/corine-land-cover (CORINE, 2017). 
Competing interests. The authors declare that they have no conflict of interest.

Acknowledgements. We are grateful to the two anonymous reviewers for their valuable comments and detailed suggestions to improve this study.

Edited by: Antonio Jordán

Reviewed by: two anonymous referees

\section{References}

Adugna, A. and Abegaz, A.: Effects of land use changes on the dynamics of selected soil properties in northeast Wellega, Ethiopia, SOIL, 2, 63-70, https://doi.org/10.5194/soil-2-63-2016, 2016.

CEC (Commission of the European Communities): Communication from the Commission to the Council, the European Parliament, the European Economic and Social Committee and the Committee of the Regions - Thematic strategy for soil protection, Commission of the European Communities. COM, Brussels, Belgium, p. 231, 2006.

CORINE: CORINE Land Cover, available at: http: //land.copernicus.eu/pan-european/corine-land-cover, last access: 16 June 2017.

Díaz-Pacheco, J. and García-Palomares, J. C.: Urban Sprawl in the Mediterranean Urban Regions in Europe and the Crisis Effect on the Urban Land Development: Madrid as Study Case, Urban Studies Research, 2014, 807381, https://doi.org/10.1155/2014/807381, 2014.

EC: Green-week events, 25 May 2011, available at: http://ec. europa.eu/environment/archives/greenweek2011/content/filmil-suolo-minacciato-land-under-threat-directed-nicoladallolio.html (last access: 16 June 2017), 2011.

EC: Financial allocations 2014-2020, available at: http://ec.europa. eu/regional_policy/thefunds/funding/index_en.cfm (last access: 16 June 2017), 2015.

EEA: Urban sprawl in Europe - the ignored challenge- EEA Report No. 10/2006, Copenhagen, Denmark, 2006a.

EEA: Land accounts for Europe 1990-2000, EEA Technical Report No. 11/2006, Copenhagen, Denmark, 2006, available at: https://www.eea.europa.eu/data-and-maps/data/land-coverflows-based-on-corine-land-cover-changes-database-1990-

2000-1 (last access: 16 June 2017), 2006b.

EEA: Changes in European land cover from 2000 to 2006, available at: https://www.eea.europa.eu/data-and-maps/figures/ land-cover-2006-and-changes-1 (last access: 16 June 2017), 2013a.

EEA: Land take. Indicator assessment, Data and maps. This report has been generated automagically by the EEA Web content management system on 22 Feb 2017, 12:08 PM, available at: http://www.eea.europa.eu/data-and-maps/indicators/ land-take-2/assessment-2 (last access: 22 February 2017), $2013 b$.

EEA: Dominant land cover flows 2000-2006, available at: https://www.eea.europa.eu/data-and-maps/figures/ dominant-land-cover-flow-2000-2006 (last access: 16 June 2017), 2013c.
EEA: SOER 2015, European briefings: Soil, available at: http: //www.eea.europa.eu/soer-2015/europe/soil (last access: 16 June 2017), 2015.

ESDAC: ESDAC data, available at: http://esdac.jrc.ec.europa.eu/content/soil-biomass-productivitymaps-grasslands-and-pasture-coplands-and-forest-areaseuropean, last access: 16 June 2017.

Gregor, M., Löhnertz, M., Philipsen, C., Aksoy, E., Schröder, C., Prokop, G., and Tramberend, P.: The report on land resource efficiency. European Topic Centre on Urban, Land and soil systems (ETC/ULS), Copenhagen, Denmark, 2015.

Helming, K., Konig, B., and Tscherning, K.: SENSOR first annual report (public part), in: SENSOR report series 2006/1, edited by: Helming, K. and Wiggering, H., ZALF, Germany, available at: http://publ.ext.zalf.de/publications/SENSORrs_2006_1_ annreport.pdf (last access: 16 June 2017), 2006.

Hoogeven, Y. and Ribeiro, T.: Land Use Scenarios for Europe, Background Report, European Environmental Agency, Kopenhagen, Denmark, 2007.

Kalema, V. N., Witkowski, E. T. F., Erasmus, B. F. N., and Mwavu, E. N.: The Impacts of Changes in Land Use on Woodlands in an Equatorial African Savanna, Land Degrad. Dev., 26, 7 632-641, https://doi.org/10.1002/ldr.2279, 2015.

Klijn, J. A., Vullings, L. A. E., Lammeren, R. J. A., van Meijl, J. C. M., van Rheenen, T., Veldkamp, A., Verburg, P. H., Westhock, H., Eickhout, B., and Tabeau, A. A.: The EURURALIS study: technical document, Alterra Report 1196, Alterra, Wageningen, the Netherlands, 2005.

Liu, Z., Yao, Z., Huang, H., Wu, S., and Liu, G.: Land use and climate changes and their impacts on runoff in the Yarlung Zangbo river basin, China, Land Degrad. Dev., 25, 203-215, https://doi.org/10.1002/ldr.1159, 2014.

Malucelli, F., Certini, G., and Scalenghe, R.: Soil is brown gold in the Emilia-Romagna region, Land Use Policy, 39, 350-357, https://doi.org/10.1016/j.landusepol.2014.01.019, 2014.

Mancosu, E., Gago-Silva, A., Barbosa, A., de Bono, A., Ivanov, E., Lehmann, A., and Fons, J.: Future land-use change scenarios for the Balck Sea catchment, Environ. Sci. Policy, 46, 26-36, https://doi.org/10.1016/j.envsci.2014.02.008, 2015.

Mohawesh, Y., Taimeh, A., and Ziadat, F.: Effects of land use changes and soil conservation intervention on soil properties as indicators for land degradation under a Mediterranean climate, Solid Earth, 6, 857-868, https://doi.org/10.5194/se-6-857-2015, 2015.

Muñoz-Rojas, M., Jordán, A., Zavala, L. M., De la Rosa, D., AbdElmabod, S. K., and Anaya-Romero, M.: Impact of Land Use and Land Cover Changes on Organic Carbon Stocks in Mediterranea n Soils (1956-2007), Land Degrad. Dev., 26, 168-179, https://doi.org/10.1002/ldr.2194, 2015.

Nabielek, K., Kronberger-Nabielek, P., and Hamers, D.: The RuralUrban Fringe in the Netherlands: a Morphological Analysis of Recent Urban Developments, Proceedings REAL CORP 2013, Tagungsband, 20-23 May 2013, Rome, Italy, 2013.

OECD: OECD Territorial Reviews, Madrid, Spain, 2007.

Parras-Alcántara, L., Martín-Carrillo, M., and Lozano-García, B.: Impacts of land use change in soil carbon and nitrogen in a Mediterranean agricultural area (Southern Spain), Solid Earth, 4, 167-177, https://doi.org/10.5194/se-4-167-2013, 2013. 
Prokop, G., Jobstmann, H., and Schönbauer, A.: Overview of best practices for limiting soil sealing or mitigating its effects in EU27. Final report, Study contracted by the EC DG Environment, https://doi.org/10.2779/15146, 2011.

Rounsevell, M. D. A., Reginster, I., Araujo, M. B., Carter, T. R., Dendoncker, N., Ewert, F., House, J. I., Kankaanpaa, S., Leemans, R., Metzger, M. J., Schmidt, C., Smith, P., and Tuck, G.: A coherent set of future land use change scenarios for Europe, Agr. Ecosyst. Environ., 114, 57-68, 2006.

Scheffer, F. and Schachtschabel, P.: Lehrbuch der Bodenkunde, Spektrum, Stuttgart, Germany, 2002.

Smith, P., Cotrufo, M. F., Rumpel, C., Paustian, K., Kuikman, P. J., Elliott, J. A., McDowell, R., Griffiths, R. I., Asakawa, S., Bustamante, M., House, J. I., Sobocká, J., Harper, R., Pan, G., West, P. C., Gerber, J. S., Clark, J. M., Adhya, T., Scholes, R. J., and Scholes, M. C.: Biogeochemical cycles and biodiversity as key drivers of ecosystem services provided by soils, SOIL, 1, 665685, https://doi.org/10.5194/soil-1-665-2015, 2015.

Tóth, G.: Impact of land take on the land resource base for crop production in the European Union, Sci. Total Environ., 435-436, 202-214, 2012.

Tóth, G., Bódis, K., Ivits, É., Máté, F., and Montanarella, L.: Productivity component of the proposed new European agrienvironmental soil quality indicator, in: Land quality and land use information in the European Union, edited by: Tóth, G. and Németh, T., Publication Office of the European Union, Luxembourg, 297-308, 2011.
Tóth, G., Gardi, C., Bódis, K., Ivits, É., Aksoy, E., Jones, A., Jeffrey, S., Petursdottir, T., and Montanarella, L.: Continental-scale assessment of provisioning soil functions in Europe, Ecol. Process., 2, 32, https://doi.org/10.1186/2192-1709-2-32, 2013.

Trabaquini, K., Formaggio, A. R., and Galvão, L. S.: Changes in physical properties of soils with land use time in the Brazilian savanna environment, Land Degrad. Dev., 26, 397-408, https://doi.org/10.1002/ldr.2222, 2015.

Van Ittersum, M. K., Ewert, F., Heckelei, T., Wery, J., Alkan Olsson, J., Andersen, E., Bezlepkina, I., Brouwer, F., Donatelli, M., Flichman, G., Olsson, L., Rizzoli, A. E., van der Wal, T., Wien, J. E., and Wolf, J.: Integrated assessment of agricultural systems A component-based framework for the European Union (SEAMLESS), Agr. Syst., 96, 150-165, 2008.

Wasak, K. and Drewnik, M.: Land use effects on soil organic carbon sequestration in calcareous Leptosols in former pastureland - a case study from the Tatra Mountains (Poland), Solid Earth, 6, 1103-1115, https://doi.org/10.5194/se-6-1103-2015, 2015. 